\title{
Olsalazine versus placebo in the treatment of mild to moderate ulcerative colitis: a randomised double blind trial
}

\author{
G E FEURLE, D THEUER, S VELASCO, B A BARRY, D WÖRDEHOFF, \\ A SOMMER, G JANTSCHEK, AND W KRUIS
}

From Stadtkrankenhaus Neuwied; Praxis Dillingen, Frankfurt-Höchst, Heilbronn; Medizinische Universitätsklinik, Köln; St. Michael Krankenhaus, Völklingen; and Medizinische Universitätsklinik, Lübeck, Federal Republic of Germany

summary The effect of olsalazine, an analogue of sulphasalazine, consisting of two molecules 5 -aminosalicylic acid linked by an azobond has been investigated for the treatment of ulcerative colitis. In a randomised double blind trial we compared $2 \mathrm{~g}$ olsalazine with placebo for four weeks. Of the 105 patients, with mild to moderate ulcerative colitis, entered in the trial 52 received olsalazine, and 53 placebo. Treatment had to be terminated prematurely because of untoward effects of olsalazine (mainly diarrhoea) in three patients and treatment failure - that is, increased rectal bleeding in four patients (olsalazine group: one placebo group: three). After four weeks' treatment, a statistically significant improvement in the endoscopic findings in rectum and a positive trend in the reduction of rectal mucus and blood discharge was observed in the patients treated with olsalazine. No statistically significant difference was found for other factors, including stool frequency, consistency, urge to defecate, abdominal pain, and biopsy findings. A comparison between these clinical and endoscopic parameters at study entry and those at study completion (within drug evaluation) showed significant improvement in six of 10 parameters during treatment with olsalazine and in two of 10 during placebo treatment. This difference suggests the significant effect of olsalazine. We conclude that $2 \mathrm{~g}$ olsalazine was tolerated as well as placebo, apart from causing diarrhoea in some patients and was slightly superior to placebo during four weeks' treatment of mild to moderate ulcerative colitis. A study with 3 or $4 \mathrm{~g}$ olsalazine per day may show a more definite effect.

Sulphasalazine has been used in the treatment of ulcerative colitis for more than 40 years. ' It is now established that it is split into sulphapyridine and 5 -aminosalicylic acid by bacteria during intestinal passage. ${ }^{3+} 5$-Aminosalicylic acid has been suggested as the therapeutically active moiety, ${ }^{5-7}$ whereas most of the side effects are attributed to the sulphapyridine part of the parent molecule. ${ }^{\text {x-11" }}$ Consequently, there have been various attempts to design drugs that

Address for correspondence: Prof Dr Gerhard E. Feurle. Stadtkrankenhaus. Markstraße 74, D-5450 Neuwied 1, FRG. deliver 5-aminosalicylic acid to the large bowel of patients with ulcerative colitis without sulphapyridine. ${ }^{11-1 x}$ One such substance is olsalazine in which two molecules of 5-aminosalicylic acid are linked by an azobond. This compound is considered ideal as absorption in the small bowel is minimal, as shown by quantitative recovery of olsalazine in ileostomy fluid, ${ }^{11}$ and because the azobond of olsalazine is effectively split by bacteria in the large bowel..$^{2121}$ In terms of 5-aminosalicylic acid $1 \mathrm{~g}$ olsalazine is equivalent to $2 \cdot 3 \mathrm{~g}$ sulphalazine." 
Table 1 Exclusion criteria

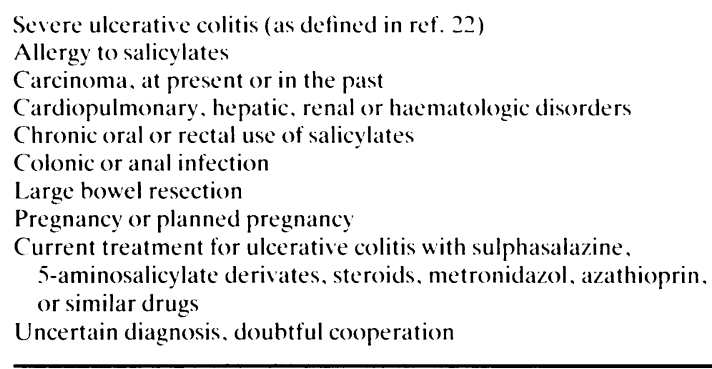

The aim of the present investigation is to determine therapeutic and untoward effects of $2 \mathrm{~g}$ olsalazine in the treatment of ulcerative colitis. For this purpose a randomised double-blind placebo controlled study was carried out in more than 100 patients.

\section{Methods}

\section{STUDY POPULATION}

With the expected efficacy of olsalazine and placebo approximately 100 patients were deemed necessary for final evaluation. Between 1984 and 198612 physicians in West Germany (cight in hospitals, four in private practice) recruited 126 outpatients with mild or moderate ulcerative colitis (age range 18-75 years). Severity of was defined according to the criteria of Truelove and Richards." Mild: occasional bloody stools and occasional mild diarrhoea. Sigmoidoscopy should show slight mucosal changes, such as light hyperaemia and granularity or petechial bleeding. Moderate: bloody diarrhoea not seriously affecting the patient's general well being. Sigmoidoscopy should show pronounced hyperaemia and enhanced mucosal fragility with occasional ulceration. Patients with severe colitis and patients currently treated with sulphasalazine, one of its analogues, steroids, metronidazol, or azathioprin were not eligible. The exclusion criteria are presented in Table 1. For ethical reasons the protocol did not permit recruitment of patients whose current treatment for ulcerative colitis was discontinued for purpose of the present study. We, therefore, enrolled only patients with their first attack of colitis or patients who had discontinued treatment and experienced a relapse.

ASSIGNMENT TO TREATMENT AND BLINDING

The patients were randomly allocated to receive $2 \mathrm{~g}$ olsalazine $(4 \times 2$ gelatin capsules) daily or eight placebo capsules with identical appearance containing $250 \mathrm{mg}$ potato starch, $18 \mathrm{mg}$ riboflavin, indigo carmine, and magnesium stearate. The blister packs holding a four weeks' supply of olsalazine or placebo were prepared by Pharmacia Uppsala, Sweden. The medication allocated for one day was divided in four doses of two capsules per blister labelled morning, noon, afternoon, and evening respectively. The patients were advised to start in the first day of treatment with less than eight capsules, to reach the complete dosage gradually within three to four days. Randomisation was done centrally, stratified in blocks of 10 for each of the 12 centres.

EFFICACY AND SAFETY VARIABI.ES

Clinical and laboratory evaluation, rectosigmoidoscopy, biopsy, and microscopic examinations were done in all patients. Clinical and laboratory examinations were scheduled at recruitment, after two weeks, and at the end of the trial after four weeks. Endoscopy and biopsy were done on days zero and 28. Clinical observations and side effects, if any, were recorded by the physicians in a protocol on day zero, 14, and 28. The endoscopic score was the mean of the parameters redness or hyperaemia, contact bleeding, spontaneous bleeding, and erosions each graded $0,1,2$. The clinical status of each patient was recorded each day on patient diary cards. The clinical score was based on the number of stools, presence of blood in stool (graded $0,1,2$ by the patient), stool consistency (graded $0,1,2$ ), and mucus in stool (graded $0,1,2)$. Appetite was graded $(0,1,2)$.

The clinical score was considered improved when at least three of these four parameters were improved. Microscopic grading was carricd out centrally, according to Truelove and Richards"2 without knowledge of the patient's history. Safety was assessed by requesting the patient to call immediately if his or her condition deteriorated and by clinical and laboratory assessment (erythrocyte count, leucocyte count, thrombocyte counts, white cell differential count, haemoglobin, SGOT, SGPT, creatinine, and blood sugar) at entry, after 14 , and after 28 days.

\section{ETHICS}

The study design was approved by the Ethics Committee of the Medizinische Poliklinik, University of Heidelberg. Informed consent, obtained from each patient, stressed that the trial was placebo controlled. The patients were assured that treatment would be stopped if complications or side effects developed. The patients recorded his or her symptoms daily on a chart.

\section{COMPLIANCE TESTING}

Compliance was tested by collecting urine and plasma during the scheduled visits after two and four weeks of treatment. The samples were frozen at $-18^{\circ} \mathrm{C}$ and analysed for olsalazine and olsalazine-(0-sulphate by Pharmacia Sweden after the study was terminated. In 
short, $4 \mathrm{ml}$ methanol was added to $1 \mathrm{ml}$ of plasma. After $30 \mathrm{~min}$ at $4^{\circ} \mathrm{C}$, the sample was centrifuged. The supernatant was used for chromatography. $1 \mathrm{ml} 0.2$ $M$ potassium phosphate, phosphate buffer $(\mathrm{pH} 7 \cdot 5)$ and $3.00 \mathrm{ml}$ methanol were added to $1 \mathrm{ml}$ urine. After centrifugation, the supernatant was used for chromatography. A LiChrosorb Si 60 column $(5 \mu \mathrm{m}$ particles, $120 \times 4.6 \mathrm{~mm}$ id) dynamically coated with cetyltrimethylammonium ions contained in the mobile phase (methanol; $0.2 \mathrm{M}$ potassium phosphate buffer $\mathrm{pH} 7.5$; water $(70: 5: 25 \mathrm{v} / \mathrm{v} / \mathrm{v})$ containing $2.5 \mathrm{mM}$ cetyltrimethylammonium bromide) was used for the separation. A saturation column (LiChroprep Si 60 15-25 $\mu \mathrm{m}$ particles, $150 \times 4.6 \mathrm{~mm}$ id) - was inserted between the pump and the injector. The injection volumc was $20 \mu \mathrm{l}$ supernatant, flow rate $1.3 \mathrm{ml} / \mathrm{min}$, and temperature $30^{\circ} \mathrm{C}$. Spectrophotometric detection was done at $365 \mathrm{~nm}$ ( $\mathrm{SH}$ Hansen et al, to be published).

\section{STATISTICAL ANALYSIS}

Binary data were compared using the $\chi^{2}$ test, ordered and continuous data were evaluated with the two sample $t$ test. All tests were carried out two sided and at the $5 \%$ level.

Treatment effects were evaluated in two ways. Within drug analysis compared the data at study entry with those at completion of the study. Between drug analysis compared the changes from baseline to four weeks of treatment between treatment groups. For patients withdrawn before four weeks of treatment, the last observed value was used (end point analysis). As we evaluated one histologic variable, eight clinical, and two endoscopic variables, the Bonferroni-Holm procedure was used to account for multiple comparisons. ${ }^{.3}$

\section{Results}

Twenty one of the 126 patients initially recruited failed to meet the inclusion criteria (Table 2). The study therefore was started with 105 patients, 52 received olsalazine and 53 placebo. There were no significant differences between the two treatment

Table 2 Exclusion because of protocol violations

\begin{tabular}{|c|c|c|}
\hline & Olsalazine & Placebo \\
\hline Current treatment with sulphalazine & 5 & \\
\hline Current treatment with steroids & 4 & 6 \\
\hline Remission at entry & & 2 \\
\hline Salicylate allergy & 1 & \\
\hline Subtotal colectomy & & 1 \\
\hline Crohn's disease & & 1 \\
\hline Unspecific proctitis & & 1 \\
\hline
\end{tabular}

Table 3 Baseline data (Mean (SD)

\begin{tabular}{|c|c|c|}
\hline & Olsalazine & Placebo \\
\hline $\mathrm{n}$ & 52 & 53 \\
\hline Women & 26 & 29 \\
\hline Men & 26 & 24 \\
\hline Age $(y r)$ & $42.9(15 \cdot 8)$ & $42 \cdot 9(16 \cdot 0)$ \\
\hline Duration of disease $(\operatorname{mos})$ & $28.5(45.9)$ & $27 \cdot 5(39 \cdot 0)$ \\
\hline Body weight $(\mathrm{kg})$ & $69 \cdot 7(12 \cdot 2)$ & $67 \cdot 2(10 \cdot 7)$ \\
\hline General well being ( $\%$ ) & $18 \cdot 2(16 \cdot 1)$ & $16 \cdot 1(13 \cdot 6)$ \\
\hline Abdominal pain $(\%)$ & $23 \cdot 3(21 \cdot 0)$ & $18 \cdot 6(19 \cdot 0)$ \\
\hline Stools last week (n) & $24(17 \cdot 2)$ & $25 \cdot 5(22 \cdot 2)$ \\
\hline Stool consistency (\%) & $45 \cdot 7(28 \cdot 6)$ & $48 \cdot 6(34 \cdot 3)$ \\
\hline Rectal bleeding & $67 \cdot 1(29 \cdot 3)$ & $60 \cdot(0)(32.9)$ \\
\hline Mucus discharge ( $\%$ ) & $55.7(33.6)$ & $47.9(27.9)$ \\
\hline Urge to defecate $(\%)$ & $40.5(29.5)$ & $30.5(31.9)$ \\
\hline Endoscopic index & $1 \cdot 1(0 \cdot 5)$ & $1 \cdot 0(0 \cdot 4)$ \\
\hline Microscopic index & $1.5(0 \cdot 6)$ & $1 \cdot 3(0 \cdot 6)$ \\
\hline Leucocytes/nl & $5999(2194)$ & $6(0)(2289)$ \\
\hline Haemoglobin g/dl & $14 \cdot 2(1 \cdot 6)$ & $14 \cdot 4(1 \cdot 3)$ \\
\hline ESR Ist h & $13 \cdot 4(13 \cdot 7)$ & $15 \cdot 8(13 \cdot 5)$ \\
\hline \multicolumn{3}{|l|}{$\begin{array}{l}\text { Previous medication in number } \\
\text { of patients }\end{array}$} \\
\hline oral sulphasalazine & 14 & 23 \\
\hline days since last dose (range) & $155(29-370)$ & $6.37(17-2119)$ \\
\hline rectal sulphasalazine & 6 & 5 \\
\hline systemic steroids & 3 & 4 \\
\hline rectal steroids & 4 & 7 \\
\hline metronidazol & 2 & () \\
\hline
\end{tabular}

The clinical parameters such as general well being, abdominal pain etc are expressed as percent of maximal possible impairment during the preceding week. The worst condition would score 100 .

groups with respect to baseline disease variables (Table 3). One centre contributed 47 of the 105 patients. The baseline or outcome data did not differ from the total study population. Twelve patients on olsalazine and nine on placebo complained of side effects, such as diarrhoea, nausea, abdominal pain and loss of appetite (Table 4); in three of them, all in

Table 4 Untoward effects

\begin{tabular}{lll}
\hline & $\begin{array}{l}\text { Atributed to } \\
\text { olsalazine }\end{array}$ & Placebo \\
\hline Digns and symptoms & $5(2)$ & 0 \\
Nausea & $2(1)$ & 2 \\
Abdominal pain & 2 & 3 \\
Cardiac palpitation & 2 & 0 \\
Sweating & 0 & 1 \\
Hair loss & 1 & 0 \\
Increased transaminases & 0 & 1 \\
Loss of appetite & 0 & 2 \\
Vomiting & 1 & 0 \\
Weakness & 1 & 1 \\
Headache & 1 & 1 \\
Abdominal bloating & 1 & 1 \\
\hline
\end{tabular}

The number of patients in whom the study was terminated because of side effects is shown in brackets. Some patients had more than one side effect. 


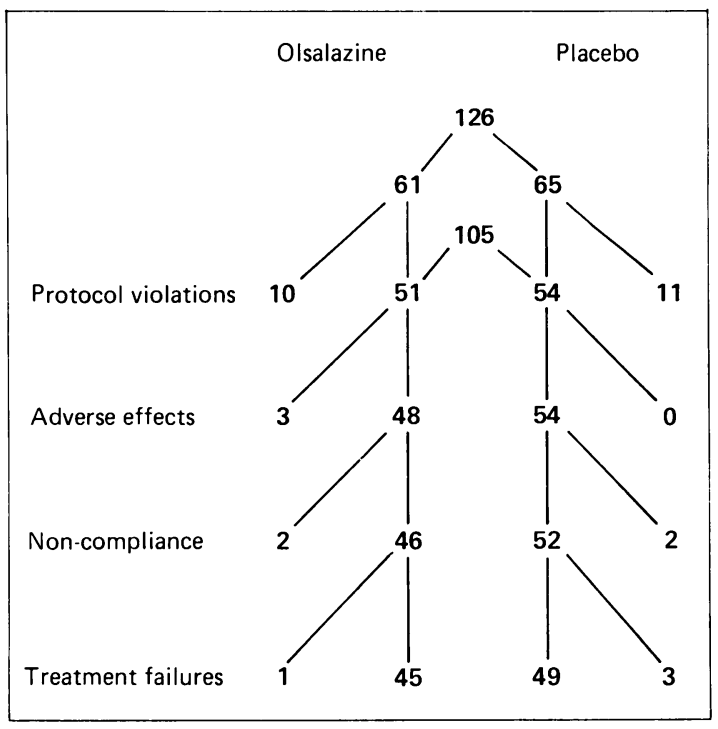

Fig. 1 Overview of the patients recruited, excluded and those who remained in the study.

the olsalazine group, the study was discontinued because of diarrhoea (two patients), nausea and abdominal pain (one patient). These courses were considered treatment failures.

In four patients the study was stopped because of increased rectal bleeding (one in the olsalazine group, three in the placebo group) and four patients desired to terminate the study (two in the olsalazine group, two of the placebo group). An overview is presented in Figure 1.

During the 28 days of the study, the patients in the olsalazine group gained $0.1(1.7) \mathrm{kg}$, the patients in the placebo group lost $0.1(1.6) \mathrm{kg}$ weight; the difference was not significant. Laboratory values remained unchanged (Table 5). Evaluation of the efficacy variables after four weeks' treatment (between drug evaluation) revealed a statistically significant improvement in rectal mucus discharge $(\mathrm{p}=0.0038)$ and a nearly significant reduction of

Table 5 Laboratory evaluation at the end of the study

\begin{tabular}{lll}
\hline & Olsalazine & Placebo \\
\hline ESR mm Ist h & $12 \cdot 5$ & $17 \cdot 0$ \\
Hb g/dl & $13 \cdot 7$ & $13 \cdot 5$ \\
Leucocytes/nl & 6113 & 6114 \\
Thrombocytes/nl & 251 & 256 \\
Differential count & unchanged & unchanged \\
Creatinine mg/dl & $0 \cdot 8$ & $0 \cdot 9$ \\
SGPT U/l & $12 \cdot 5$ & $13 \cdot 8$ \\
SGOT U/l & $12 \cdot 0$ & $12 \cdot 8$ \\
\hline
\end{tabular}

Table 6 Significance levels ( $p$-values) of efficacy parameters

\begin{tabular}{|c|c|c|c|}
\hline & \multicolumn{2}{|c|}{ Within drug analysis } & \multirow{2}{*}{$\begin{array}{l}\text { Between } \\
\text { drug analysis }\end{array}$} \\
\hline & Olsalazine & Placebo & \\
\hline General well being & $0 \cdot 012$ & 0.075 & NS \\
\hline Abdominal pain & $0 \cdot 041$ & NS & NS \\
\hline Stools/week (n) & 0.058 & NS & NS \\
\hline Stool consistency & NS & NS & NS \\
\hline Blood in stool & $<0 \cdot 001$ & $<0 \cdot 001$ & 0.0536 \\
\hline Mucus in stool & $<0 \cdot 001$ & $0 \cdot 061$ & 0.0038 \\
\hline Urge to defecate & NS & NS & NS \\
\hline Appetite & NS & NS & NS \\
\hline Endoscopic score rectum & $<0.001$ & 0.0279 & $0 \cdot 0127$ \\
\hline Endoscopic score sigma & $<0 \cdot 001$ & NS & NS \\
\hline Microscopic score & - & - & NS \\
\hline Clinical score & - & - & NS \\
\hline
\end{tabular}

Within drug analysis indicates the change of the parameters from baseline to study completion. Between drug analysis indicates difference of the parameters in the olsalazine and placebo group at completion of the study. The exact $p$ values are given when they were close to $0 \cdot(0)$.

rectal bleeding in the olsalazine group $(p=0.0536)$ (Table 6). All other clinical parameters such as general well being, abdominal pain, appetite, stool consistency, urge to defecate, and stool frequency, as well as the composed clinical index did not significantly differ from the placebo group (Table 6). The course of some of these clinical parameters indicates a trend in favour of the efficacy of olsalazine (Fig. 2) as do the $95 \%$ confidence intervals for the difference between treatment groups (Fig. 3).

Rectoscopy carried out at the beginning and the end of the study in 98 patients revealed an improvement of the mean endoscopic score - that is, reduction of inflammation in $61.7 \%$ of the patients on olsalazine and $46 \%$ of the patients on placebo, $(p=0 \cdot 0127)$.

A trend towards improvement of the endoscopic findings in the sigma was observed in the 69 patients with sigmoidoscopy at study entry and at termination $(61.8 \%$ of the patients on olsalazine showed improvement versus $34.3 \%$ of the patients on placebo $p=0 \cdot 1673$ (Table 6 ). In 93 patients who were biopsied at the beginning and end of the study assessment the microscopic findings in the rectal mucosa revealed reduced inflammation in $25.6 \%$ of the group on olsalazine and in $29.6 \%$ of the group on placebo (not significant). (Table 6). The improvements of mucus discharge and endoscopic appearance of rectum remain statistically significant even when accounted for multiple comparisons.

Within drug evaluation (change from the baseline) is also shown in Table 6 . In the olsalazine group, a significant improvement was recorded in six of 10 parameters (general well being, abdominal pain, 
rectal bleeding, mucus admixture, endoscopic score rectum, and sigma), whereas rectal bleeding and the rectal endoscopic score improved significantly also in the placebo group.

The improvements of mucus and blood discharge and of the endoscopic findings in rectum and sigma remain significant even when the BonferroniHolm procedure is used to account for multiple comparisons.

\section{COMPLIANCE}

The concentrations of olsalazine and its metabolite olsalazine sulphate in the patients allocated to the olsalazine group are presented in Table 7. The rapidly excreted olsalazine (plasma in half life of ca one day) found in low concentrations in the plasma but in high concentrations in the urine served as indicator of drug intake during the preceding day. By contrast, olsalazine sulphate (plasma half life of approximately five days) found in relatively high concentrations in plasma, and in low concentrations in the urine served as an indicator of drug intake during the last week of treatment. Detailed analysis revealed olsalazine and olsalazine sulphate in plasma and urine after 14 days in three patients; on day 28 , however, olsalazine and olsalazine sulphate excretion in these patients was below the detection limit (20 $\mu \mathrm{mol})$ whereas plasma olsalazine sulphate concentrations were raised. This suggests that these patients were not taking olsalazine during the second half of the study. Plasma samples were not available in one patient with low urinary drug levels at days 14 and 28 and neither plasma nor urine samples were provided by four patients. It must be assumed that these five patients had not taken olsalazine regularly during the study and that the other three patients mentioned had not taken the drug during the second half of the study. The overall compliance with respect to drug intake, therefore, was $82.6 \%(38 / 46)$ of the patients completing trial. The fact that two of the patients randomised to placebo had low but detect-

Table 7 Olsalazine and olsalazine sulphate concentrations in plasma and urine ( $\mathrm{mmol}$; Mean SD)

\begin{tabular}{llll}
\hline \multicolumn{1}{c}{ After 14 days } & After 28 days \\
\hline \multirow{3}{*}{ Urine } & Olsalazine & $27 \cdot 81(41 \cdot 71)$ & $20 \cdot 32(29 \cdot 19)$ \\
& & $n=41$ & $\mathrm{n}=44$ \\
& Olsalazine sulphate & $3 \cdot 59(5 \cdot 48)$ & $3 \cdot 22(4 \cdot 13)$ \\
& & & \\
\multirow{2}{*}{ Plasma } & & $0 \cdot 63(0 \cdot 52)$ & $0 \cdot 54(0 \cdot 45)$ \\
& Olsalazine & $n=32$ & $n=34$ \\
& & $8 \cdot 43(6 \cdot 49)$ & $10 \cdot 11(7 \cdot 15)$ \\
& $n=35$ & $n=35$ \\
\hline
\end{tabular}

$\mathbf{n}=$ number of samples available able drug levels in urine and plasma at day 28 (not at day 14) suggests that these two patients in the placebo group had either taken some olsalazine or another cross-reacting 5-aminosalicylic acid containing compound during the second half of the trial.

\section{Discussion}

Although we studied in a large trial an 'ideal' drug that delivers the active moiety of sulphasalzine to the colon, we found that olsalazine had only a slight advantage over placebo in the treatment of mild to moderate ulcerative colitis. This was an unexpected finding in light of two previous trials in which sulphasalazine was significantly more efficacious than placebo in approximately 40 patients with mild to moderate colitis. ${ }^{2425}$ Three more recent studies tested olsalazine versus placebo in ulcerative colitis. ${ }^{2 k-2 x}$ Selby et al studied 40 patients for two weeks and

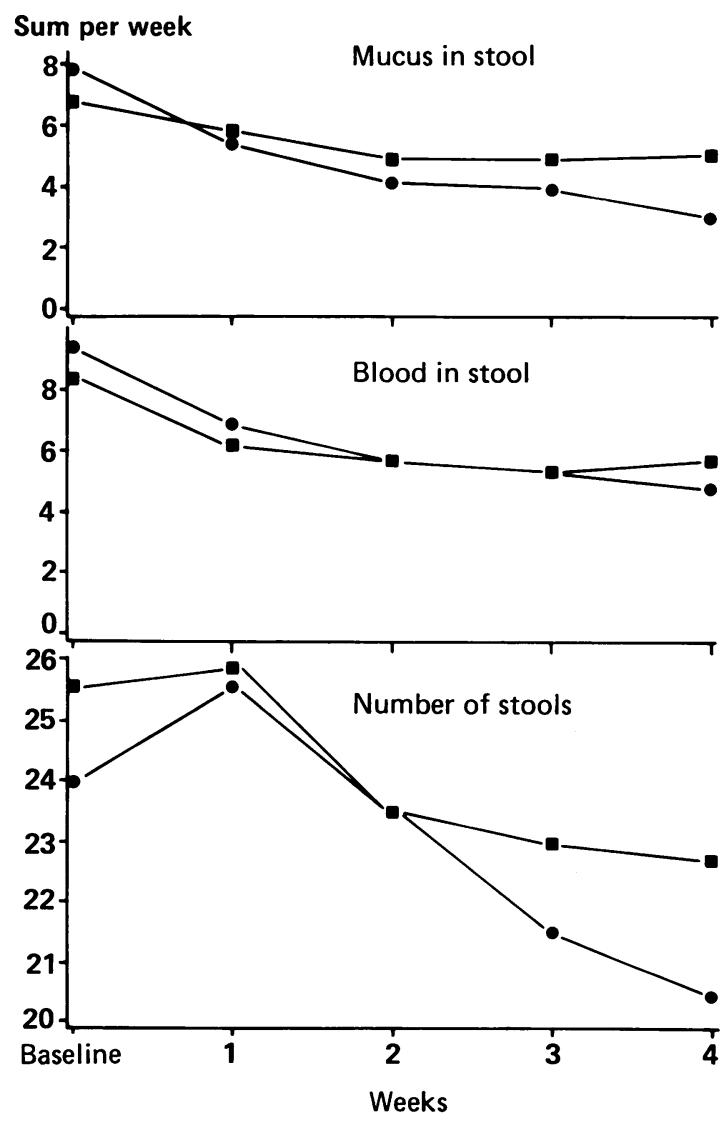

Fig. 2 Course of the mean scores for mucus and blood in stools (each graded 0,1,2) per week and the number of stools per week during four weeks treatment with olsalazine (O) or placebo ( $)$ as taken from the patients diaries. 


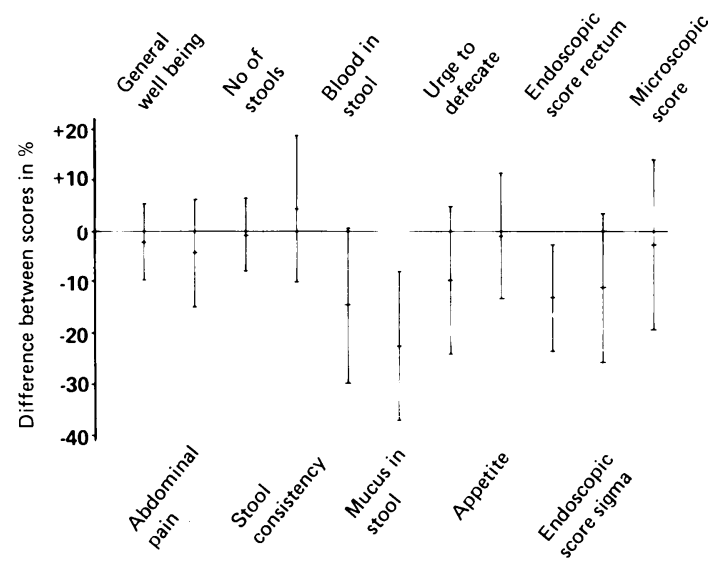

Fig. $395 \%$ confidence intervals of the difference between the treatment groups in change from baseline. Variables, except number of stools, have been expressed as percent of maximal possible score. The worst condition would score 100. A negative difference (olsalazine-placebo) means reduction of severity of the colitis during treatment with olsalazine as compared with placebo.

found olsalazine significantly superior.$^{-6}$ Hetzel et al detected no significant effect in 30 patients treated for six weeks ${ }^{27}$ and Meyers $e t$ al in a dose response study reported a significant effect of olsalazine in 66 patients treated for three weeks when colitis activity at study entry was compared with colitis activity at completion of the study. ${ }^{28}$
Our trial also showed an advantage of olsalazine over placebo when the clinical and endoscopic findings after treatment were compared with those obtained at the beginning of the study (Table 6). General well being, abdominal pain, blood and mucus in stools, and endoscopic appearance of rectum and sigma were significantly improved during treatment with olsalazine, whereas in the placebo group only rectal bleeding and endoscopic findings in the rectum improved. After application of the Bonferroni-Holm test ${ }^{23}$ to account for multiple statistical comparisons, a significant advantage of olsalazine over placebo is maintained. Conventional analysis of clinical, endoscopic, and microscopic findings after treatment with olsalazine or placebo at the end of the study, however, showed that only mucus discharge and rectal endoscopic findings were significantly improved in the patients treated with olsalazine.

It is of interest, however, that the $95 \%$ confidence intervals indicate improvement of 10 of 11 parameters during treatment with olsalazine (Fig. 3). The exception of stool consistency may relate to an adverse effect of olsalazine that is known to cause diarrhoea in some patients.

It is unlikely that the unexpected weak effect of olsalazine is the result of a lack of compliance as we have evidence that $82.6 \%$ of the patients in the olsalazine group finishing the study took olsalazine and as $95.6 \%$ of the patients in the placebo group had no detectable concentrations of olsalazine or its

Table 8 Response (percentage of the patients improving) in treatment trials of ulcerative colitis

\begin{tabular}{|c|c|c|c|c|}
\hline Study & Parameter & Sulphasalazine & Placebo & Significance \\
\hline \multirow{2}{*}{ Baron et $a l^{2}$} & Clinical score & 80 & 35 & $\mathrm{~S}$ \\
\hline & Endoscopic score & 80 & 40 & S \\
\hline \multirow[t]{2}{*}{ Dick et $a l^{-}$} & Clinical score & 67 & 44 & S \\
\hline & Endoscopic score & 83 & 26 & S \\
\hline & & olsalazine & placebo & \\
\hline \multirow[t]{2}{*}{ Selby et $a l^{\prime \prime}$} & Clinical score & 65 & 40 & $\mathrm{~S}$ \\
\hline & Endoscopic score & 45 & 35 & $\mathrm{~S}$ \\
\hline \multirow[t]{2}{*}{ Hetzel et al } & Clinical score & 46 & 22 & NS \\
\hline & Endoscopic score & 46 & 22 & NS \\
\hline Meyers et $a l^{\mathrm{x}}$ & Clinical score & 35 & 16 & not stated \\
\hline \multicolumn{5}{|l|}{ Present study } \\
\hline & Clinical score & 52 & 45 & NS \\
\hline & Endoscopic score rectum & 62 & 46 & S \\
\hline & Endoscopic score sigma & 62 & 34 & $\mathrm{~S}$ \\
\hline & General well being & 51 & 54 & NS \\
\hline & Abdominal pain & 51 & 52 & NS \\
\hline & Number of stools & 49 & 61 & NS \\
\hline & Consistency of stools & 45 & 49 & NS \\
\hline & Blood in stools & 69 & 61 & NS* \\
\hline & Mucus in stools & 71 & 62 & $\mathrm{~S}$ \\
\hline & Urge to defecate & 48 & 33 & NS \\
\hline
\end{tabular}

${ }^{*} \mathrm{p}=0.0589$ 
metabolite in plasma or urine. One reason may be a beta error - that is, reporting no difference when in fact a difference exists. The wide confidence intervals of the biologic test parameters (Fig. 3) tend to support this possibility. Previous studies comparing sulphasalazine or olsalazine to placebo, however, encompassed even smaller groups of patients. But these studies may not be comparable with our investigation. The healing rates were approximately $40 \%$ in the placebo groups and only $16 \%$ in the most recent study from New York ${ }^{2 x}$ whereas more than $60 \%$ of our patients on placebo reported a reduction of stool frequency, rectal blood, and mucus discharge (Table 8 ). This difference may be caused by different study populations or by a change in the course of the disease within the two decades between earlier sulphasalazine studies and our olsalazine trial; but widely differing placebo healing rates may also depend on geographic variation even within Europe as shown for duodenal ulcer healing. ${ }^{2 \varphi}$ In any case it would be of interest to study whether sulphasalazine would be able to cope with today's placebo in the treatment of ulcerative colitis. In some of the previous reports the definition of a clinical response was to some extent a subjective judgement. ${ }^{2528}$ In another study a clinical response was defined as improvement in any of the symptoms, number and consistency of stools, presence of blood, mucus, and abdominal pain' ${ }^{26}$ No details are given about how the overall clinical response was assessed when one parameter was reduced and another increased. One additional reason for the apparently weak effect of olsalazine in the present trial may be under dosage. It has been shown that $3 \mathrm{~g}$ olsalazine are more effective than $1.5 \mathrm{~g} .{ }^{28}$ If, as was suggested, the metabolite 5aminosalicylic acid does represent the therapeutically active moiety of sulphasalazine, ${ }^{5-7}$ our dose of $2 \mathrm{~g}$ olsalazine, equivalent to $4.6 \mathrm{~g}$ sulphasalazine $\mathrm{e}^{21}$ is well above the recommended dose. ${ }^{231}$ Because olsalazine effectively delivers 5-aminosalicylic acid to the colon, ${ }^{19-21}$ the slight effect of $2 \mathrm{~g}$ olsalazine in our trial casts doubt on the concept of 5-aminosalicylic acid as the sole active principle of sulphasalazine. In fact, in the studies on which the 5-aminosalicylic acid concept is based 5-aminosalicylic acid was applied topically by enemas or suppositories ${ }^{5-7}$ delivering rectal drug concentrations far higher than those achievable orally. Moreover, recent observations that sulphasalazine is more potent than 5-aminosalicylic acid in inhibiting lipoxygenase ${ }^{31}$ and inflammation related sulphidopeptide-leucotriene release from human colonic mucosa in vitro ${ }^{32}$ indicate that sulphasalazine may possess an intrinsic, therapeutic activity.

Evidence, therefore, suggests that treatment of patients suffering from ulcerative colitis should at present not be routinely changed to one of the newer 5 -aminosalicylic acid preparations if sulphasalazine is tolerated. A study with a larger dosage (3-4 g) olsalazine may be necessary before the role of olsalazine in the treatment of ulcerative colitis can be definitely evaluated. Such a study cannot be replaced by investigations comparing olsalazine with sulphasalazine. We are aware of two such trials: Ewe et al who investigated 40 patients for two weeks in a crossover study ${ }^{33}$ and Willoughby et al who studied 56 patients for five weeks ${ }^{34}$ reported no difference. Such studies require much larger groups of patients if differences of drug efficacy are to be detected.

Our trial shows that $2 \mathrm{~g}$ olsalazine per day are well tolerated. The only untoward effect was diarrhoea in five patients; in two the trial was stopped. Diarrhoea has been reported as a side effect of olsalazine in approximately $10 \%$ of the patients with ulcerative colitis, particularly in those with total colitis. ${ }^{35}$ The diarrhoea is seldom severe and frequently disappears probably by adaptation even when treatment is resumed after an interval of some days. ${ }^{36}$ No severe side effect or changes in laboratory values were found in our trial nor in earlier studies. ${ }^{20-2 \times 3 \times 3+37}$

On the basis of our findings, we conclude that $2 \mathrm{~g}$ olsalazine is safe but only modestly effective in the treatment of ulcerative colitis. Like with sulphasalazine, however, the main use of olsalazine may be to prevent relapse once remission has been achieved by steroids. Actually, olsalazine was significantly more effective than placebo in preventing recurrence of ulcerative colitis in 100 patients intolerant to sulphasalazine $^{35}$ and, like sulphalsalazine in maintaining remission. ${ }^{3 *}$ The main use of olsalazine, therefore, may not be the treatment of active colitis but rather the prevention of recurrence. This conclusion, however, may have to be modified after a study with a higher dosage of olsalazine.

We are obliged to Prof H F Otto, Pathologisches Institut, University of Heidelberg for the microscopical analysis of the biopsies.

The data have been previously published in abstract form: Gastroenterology 1988; 94: A126 and Scand J Gastroenterol 1988; 23: (suppl 148): 38-9.

\section{References}

1 Svartz N. Salazopyrin: a new sulfanilamide preparation. Acta Med Scand 1942; 110: 577-98.

2 Watkinson W. Sulphasalazine: a review of 40 years' experience. Drugs 1986; 32 (Suppl I): 1-11.

3 Peppercorn MA, Goldmann P. Distribution studies of salicylazosulfapyridine and its metabolites. Gastroenterology $1973 ; 64: 240-5$.

4 Das KM, Rubin R. Clinical pharmacokinetics of sulphasalazine Clin Pharmacokinet 1976; 1: 406-25. 
5 Azad Khan AK, Piris J, Truelove S. An experiment to determine the active therapeutic moiety of sulphasalazine. Lancet 1977; ii: 892-5.

6 Klotz U, Maier K. Fischer C. Heinkel K. Therapeutic efficacy of sulfasalazine and its metabolites in patients with ulcerative colitis and Crohn's disease. $N$ Engl J Med 1980; 303: 1499-502.

7 van Hees PAM, Bakker JH, van Tongeren JHM. Effects of sulphapyridine, 5-aminosalicylic acid, and placebo in patients with idiopthic proctitis: a study to determine the active therapcutic moiety of sulphasalazine. Gut 1980; 21: 632-5.

8 Schröder J, Evans DAP. Acetylator phenotype and adverse effects of sulphasalazine in healthy subjects. Gut 1972; 13: 278-84.

9 Das KM, Eastwood MA. McManus JPA. Sircus W. Adverse reaction during salicylazosulfapyridine therapy and the relation with drug metabolism and acetylator phenotype. N Engl J Med 1973; 289: 491-5.

10 van Hecs PAM, van Elteren Ph, van Rossum JM, van Tongeren JM. Hacmolysis during salicylazosulfapyridine (Salazopyrin) therapy. Am J Gastroenterol 1979; 70: $501-5$.

11 Rasmussen SN, Bondesen S, Hvidberg EF, et al. 5-Aminosalicylic acid in a slow-release preparation: bioavailability, plasma levels and excretion in humans. Gastroenterology 1982; 83: 1062-70.

12 Dew MJ, Hughes PJ, Lec MG, Evans BK, Rhodes J. An oral preparation to release drugs in the human colon. $\mathrm{Br}$ J Clin Pharmacol 1982; 14: 405-8.

13 Willoughby CP, Aronsson JK, Agback HA, Bodin NO, Truelove SC. Distribution and metabolism in healthy voluntecrs of disodium azodisalicylate. A potential therapcutic agent for ulcerative colitis. Gut 1982; 23: 1081-7.

14 Bartalsky A. Salicylazobenzoic acid in ulcerative colitis. Lancet 1982; i: 960.

15 Chan RP. Pope DJ, Gilbert AD, Sacra PJ, Baron JM, Lennard-Jones JE. Studies on two novel sulphasalazine analogs, Ipsalazide and Balsalazide. Dig Dis Sci 1983; 18: $107-11$.

16 Brown JP, McGarraugh GV, Parkinson TM, Wingard RE, Onderdonk AB. A polymeric drug for treatment of inflammatory bowel discase. J Med Chem 1983; 26: $1300-7$.

17 Klotz U, Maier K. Fischer C. Bauer KH. A new slowrelease form of 5-aminosalicylic acid for the oral treatment of inflammatory bowel disease. Biopharmaceutic and clinical pharmacokinetic characteristics. Drug Res 1985; 35: 636-9.

18 Hawkey CJ. Salicylates for the sulfa-sensitive patient with ulcerative colitis? Gastroenterology 1986; 90: 1082-4.

19 Sandberg-Gertzén, Ryde M, Järnerot G. Absorption and excretion of a single $1 \mathrm{~g}$ dose of azodisal sodium in subjects with ileostomy. Scand J Gastroenterol 1983; 18: $107-11$.

20 Lauritsen K, Hansen J, Ryde M, Rask-Madsen J. Colonic azodisalicylate metabolism determined by in vivo dialysis in healthy volunteers and patients with ulcerative colitis. Gastroenterology 1984; 86: 1496-500.

21 van Hogezand RA, von Hees PAM, Zwanenburg B, von Rossum JM, van Tongeren JHM. Disposition of disodium azodisalicylate in healthy subjects. Gastroenterology 1985; 88: 717-22.

22 Truelove SC, Richards WCD. Biopsy studies in ulcerative colitis. Br Med J 1956; i: 1315-8.

23 Holm SA. A simple sequentially rejective multiple test procedure. Scand J Statist 1979; 6: 65-70.

24 Baron JH, Connell AM, Lennard-Jones JE, Avery Jones F. Sulphasalazine and salicylazosulphadimidine in ulcerative colitis. Lancet 1982; i: 1094-6.

25 Dick AP, Grayson MJ, Carpenter RG, Petric A. Controlled trial of sulphasalazine in the treatment of ulcerative colitis. Gut 1964; 5: 437-42.

26 Selby WS, Barr GD. Ireland A, Mason $\mathrm{CH}$, Jewell DP. Olsalazine in active ulcerative colitis. $\mathrm{Br}$ Med J 1985; 291: 1373-5.

27 Hetzel DJ, Shearman DJC, Bochner F, et al. Azodisalicylate (Olsalazine) in the treatment of active ulcerative colitis. A placebo controlled clinical trial and assessment of drug disposition. J Gastroenterol Hepatol 1986; $1: 257-66$.

28 Meyers S, Sachar DB, Present DH, Janowitz HD. Olsalazine sodium in the treatment of ulcerative colitis among patients intolerant to sulfasalazine. A prospective, randomized, double-blind clinical trial. Gastroenterology 1987; 93: 1255-62.

29 Sonnenberg A, Müller-Lisner SA, Vogel E, et al. Predictors of duodenal ulcer healing and relapse. Gastroenterology 1984; 81: 1061-7.

30 Cello JP. Ulcerative colitis. In: Sleisenger MH, Fordtran JS, eds. Gastrointestinal disease. Philadelphia: WB Saunders, 1983: 1112-68.

31 Hawkey CJ, Boughton-Smith NK, Whittle BJR. Modulation of human colonic arachidonic acid metabolism by sulfasalazine. Dig Dis Sci 1985; 30: 1161-5.

32 Peskar BM, Dreyling KW, Peskar BA, May B, Goebell $\mathrm{H}$. Enhanced formation of sulfidopeptide-leukotrienes in ulcerative colitis and Crohn's disease: inhibition by sulfasalazine and 5-aminosalicylic acid. Agents Actions 1986; 18: 381-3.

33 Ewe K. Eckardt V, Kanzler G. Treatment of ulcerative colitis with olsalazine and sulphasalazine: efficacy and side-cffects. Scand J Gastroenterol 1988; 23 (suppl 148): $70-5$.

34 Willougby CP, Cowan RE, Gould SA, Machell RJ, Stewart JB. Double-blind comparison of olsalazine and sulfasalazine in active ulcerative colitis. Scand J Gastroenterol 1988; 23 (suppl 148): 40-4.

35 Sandberg-Gertzén H, Järnerot G, Kraaz W. Azodisal sodium in the treatment of ulcerative colitis. Gastroenterology 1986; 90: 1024-30.

36 Berglindh $T$. Landström $E$, Bergqvist $E$. Induction of and adaptation to olsalazine induced intestinal volume load. Scand J Gastroenterol 1988; 23 (suppl 148): 24-8.

37 Rao SS. Cann PA. Holdsworth CD. Clinical experience of the tolerance of mesalazine and olsalazine in patients intolerant of sulphasalazine. Scand J Gastroenterol 1987; 22: 332-6.

38 Jewell DP. Ireland A. Controlled trial comparing olsalazine and sulphasalazine for maintenance treatment of ulcerative colitis. Scand J Gastroenterol 1988; 23 (suppl 148): 45-7. 